Available online at_www.iponlinejournal.com

\title{
Analytical aspects and management of copper poisoning- A review
}

\author{
A.K.Jaiswal ${ }^{1 *}$, Dimple Bhatia ${ }^{2}$ Rajesh $^{3}$, M.Gupta $^{4}$, T.Millo $^{5}$ \\ ${ }^{1}$ Chemist, ${ }^{2}$ Student, ${ }^{3}$ Assistant Professor, ${ }^{4}$ Scientist, ${ }^{5}$ Professor, ${ }^{1,3,5}$ Dept. of Forensic Medicine \& Toxicology, ${ }^{2}$ Dept. of Forensic Science, \\ ${ }^{4}$ Dept. of Pharmacology, ${ }^{\mathbf{1 , 4 5}}$ All India Institute of Medical Sciences, New Delhi, ${ }^{2}$ Kurukshetra University, Kurukshetra, Haryana, ${ }^{\mathbf{3}}$ Army \\ College of Medical Sciences, Delhi Cantt, New Delhi, India
}

\begin{abstract}
Copper resembles reddish-orange when freshly exposed. It is soft, malleable and ductile metal. It is an essential trace element present in human beings and helps in biological functioning of so many enzymes in our body. Copper is also used in others places like in pesticides, alloys and due to its high conductivity to heat and electricity it is used in electrical equipments such as wiring and motors. In its metallic state copper is not as such poisonous but some of its salts are poisonous like copper sulphate, copper subacetate, copper carbonate and its accumulation in body also cause disease in humans. The toxicity cause by copper is known as copperiedus. Source of exposure to copper toxicity or copperiedus is occupational (like people working in alloy factories or pesticides industries) and non-occupational which is through contaminated water or food. Pathway of exposure is mainly through skin, gastrointestinal track, lungs and mucous membrane. Copper poisoning has both acute and chronic effect on human body.
\end{abstract}

Keywords: Copper, exposure, Fatal period and fatal dose, Toxicity, Management etc.

\section{Introduction}

Copper is a member of the first row transition series of elements with chemical symbol $\mathrm{Cu}$ and atomic number 29. It is a soft, malleable, and ductile metal with very high thermal and electrical conductivity. It resembles reddishorange when freshly exposed. It is an essential trace element present in human beings and helps in biological functioning of so many enzymes in our body. In human beings, copper exists in its two oxidation forms - the first $(+1)$ and second $(+2)$ oxidation state, as most of the copper in the human is in the second $(+2)$ oxidation state. Copper plays an important role in human body, so its deficiency can cause many disease like neutropenia, bone abnormalities, hypopigmentation, impaired growth, increased incidence of infections, osteoporosis, hyperthyroidism but its accumulation also cause some disease like Wilson's disease. Pure metallic copper is not poisonous but many salts of copper are poisonous. The salts of copper like copper sulphate, copper carbonate, copper subacetate are used for suicidal and homicidal purposes. The toxicity caused by copper is known as copperiedus. Copper is a very common substance that occurs naturally in the environment and spreads in the environment through natural phenomena, like wind-blow dust, forest fire, decaying vegetation etc. and other human activity. Most copper compounds will settle and be bound to either water sediment or soil particles. Soluble copper compounds form the largest threat to human health. Usually water-soluble copper compounds occur in the environment after release through application in agriculture and also by industrial waste. ${ }^{1-3}$

\section{Different salts of copper Copper sulphate}

It is known as cupric sulfate or copper sulphate. It is an inorganic compound with the chemical formula $\mathrm{CuSO}_{4}$ and is the most common form (Fig. 1a). Older names for this compound include blue vitriol, bluestone, vitriol of copper and Roman vitriol. It is the most common salt of copper used for suicidal as well as homicidal purposes. ${ }^{4}$

\section{Copper carbonate}

It is also known as copper (II) carbonate with chemical formula $\mathrm{CuCO}_{3}$ (Fig. 1b). Other name of copper carbonate is copper (II) carbonate hydroxide (Fig. 2). It is an ionic compound (a salt) consisting of the ions copper (II) $\mathrm{Cu}^{2+}$, carbonate $\mathrm{CO}_{3}^{2-}$, and hydroxide $\mathrm{HO}^{-}$. It is a green crystalline solid that occurs in nature as the mineral malachite and its common names are verditer, green bice, or mountain green. It has been used since antiquity as a pigment, and it is still used as such in artist paints and as cosmetics dye. ${ }^{5}$

\section{Copper acetoarsenite}

It is commonly known as Paris green (Fig.1c). It is an inorganic compound. It is a highly toxic emerald-green crystalline powder and used as a rodenticide and insecticide and also as a pigment, despite of its toxicity. It is also used as a blue colorant for fireworks. The color of Paris green is said to range from a pale blue green when very finely ground, to a deeper green when coarsely ground. It is prepared by combining copper (II) acetate and arsenic trioxide $^{6}$.

\footnotetext{
*Corresponding Author: A.K.Jaiswal, Dept. of Forensic Medicine \& Toxicology, ${ }^{5}$ All India Institute of Medical Sciences, New Delhi, India

Email: ashokjaiswal72@gmail.com

http://doi.org/ 10.18231/J.IJFCM.2019.026
} 


\section{Copper arsenite}

It is commonly known as Scheele's Green (Fig.1d), chemically it is cupric hydrogen arsenite with chemical formula $\mathrm{CuHAsO}_{3}$. Chemically it is related to Paris Green. It is a yellowish-green pigment and was used in some paints in the past and now it has fallen out of use because of its toxicity. $^{7}$

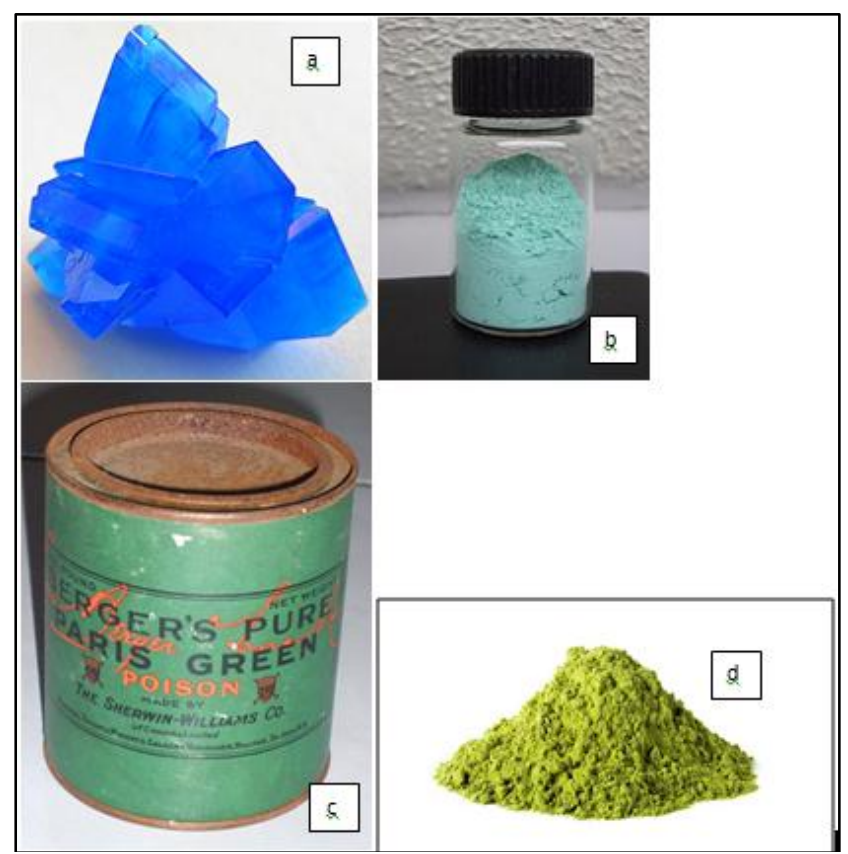

Fig. 1: Different forms of copper. (a): Crystal of copper sulphate. (b): Copper carbonate. (c): Paris green (copper acetoarsenite). (d): Scheel's green (copper arsenite)

\section{Sources of copper}

1. Naturally copper is not found pure.

2. Copper is present in soil, average copper levels in soil is $13-14 \mathrm{mg}$ per $\mathrm{kg}$. It accumulates by the process of bioaccumulation of metal in the surface horizons.

3. Compounds made up of copper are widely used in agriculture as in pesticides, rodenticides etc.

4. Copper is widely used to form alloy like Brass (an alloy of zinc and copper).

5. As salts of copper are of different colour so they are used as colouring agents.

6. Copper is also present in running water, average amount of copper present in normal running water is $0.88 \mu \mathrm{g} / \mathrm{L}$.

7. Copper particles are also present in atmosphere and are released in atmosphere by ore processing facilities, volcanic eruption, windblown dust.

8. Copper is also present in food materials like fruits (litchis, grapes, kiwi fruit, etc.) and vegetables (spinach, potato, mushroom, etc.). ${ }^{1,8}$

\section{Exposure}

\section{Occupational}

Person working in copper mining or in industry of processing the ore, they can be exposed to copper by inhalation of copper contaminated air or by contact of copper with skin. Farmers get exposed to copper during spraying of insecticides/ pesticides in the fields. Workers working in pesticides industry are at high risk of copper exposure. Copper alloys manufacturing industry's worker are also at high risk to copper exposure. ${ }^{1,8,9}$

\section{Domestic}

Copper can accumulate by consuming drinking water with high copper content. Some municipal corporations add copper sulphate to drinking water to kill yeast and fungi. It is also added to swimming pools and sometimes sprayed on fruits and vegetables to retard growth of algae and fungi. Birth control pills and intrauterine device like Copper-T tends to raise the copper level in body of females. Many food materials today we consume are high in copper like soybeans, nuts, grains etc. Fast food consumed today are also contain high copper content. Frequently using cookware made up of copper can cause copper toxicity. Inhalation of tobacco smoke can also cause accumulation of copper. $^{1,8,9}$

\section{Environmental}

Environmental exposure of copper can be caused by many ways like inhalation, ingestion and dermal exposure. Copper is present in atmospheric dust and due to inhalation of this air human are exposed to copper. Direct contact with soil containing high copper level can cause copper exposure. ${ }^{1,8,9}$

\section{Pharmaco-kinetics of copper \\ Absorption}

In our body total copper content is $150 \mathrm{mg}$. $30 \%$ of total copper intake are absorbed from the gastrointestinal tract (mainly from small intestine and also from stomach and duodenum). After coming into blood vascular system, initially copper bounds to the albumin and then transported to liver via the hepatic portal circulation where it is incorporated into ceruloplasmin (a blue metalloprotein that contain copper). In serum copper is present in two formsone is tightly bound to ceruloplasmin (93\%) and other which is loosely bound to albumin and amino acids (7\%). Complex of copper and albumin represents toxicological active portion of copper present in serum. ${ }^{10,11}$

\section{Distribution}

Copper is transport systemically from liver to other body cells or tissues primarily as ceruloplasmin. Distribution of copper occurs to all tissues of the body with the highest concentration in heart, liver, brain, muscle and kidney. Predominantly copper is bound to metallothionein (A family of cysteine rich low molecular weight proteins which bound to heavy metals like zinc, copper, mercury) inside the cell. Extensively copper is found in erythrocytes as erythrocuprein and other proteins. ${ }^{10,11}$

\section{Excretion}

Excretion of copper mainly occurs through the bile. $80 \%$ of the copper is excreted from biliary and fecal excretion and 
approximately $4 \%$ is excreted through urine. Chelation of copper is done by vitamin $\mathrm{C}$ and it facilitates its removal. In liver zinc and manganese displace copper and help in its excretion. Sulphur and molybdenum also binds to copper and help in its excretion. ${ }^{10,11}$

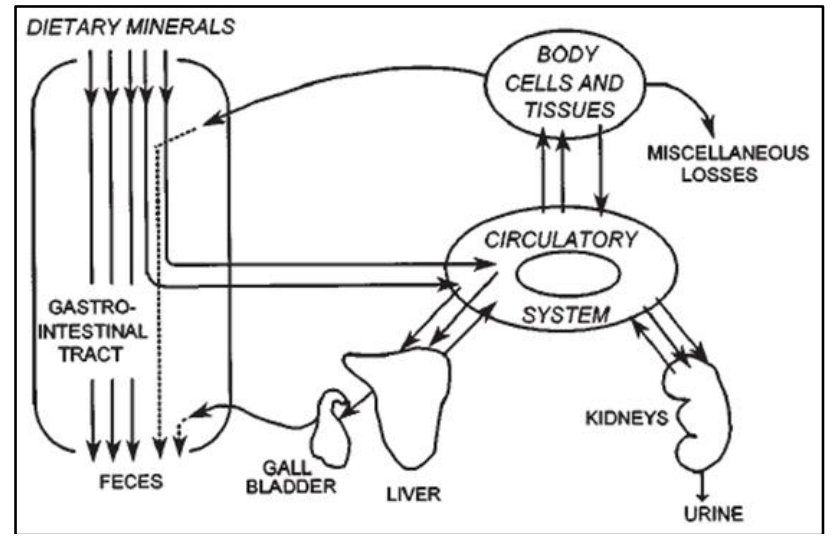

Fig. 5: Absorption, distribution and excretion of copper in human. $^{11}$

\section{Mechanism of action/toxicity}

Copper sulphate is mostly used for suicidal purposes in India rather than other salts of copper. It has strong oxidizing power and it is corrosive to mucous membranes. Concentration solution of copper sulphate is acidic in nature with $\mathrm{pH} 4$. Necrosis occurs due to accumulation of excess copper inside the cell, due to which free reduced copper binds with sulphydryl groups (R-SH) and cause inactivation of certain enzymes like glucose-6-phosphate dehydrogenase and glutathione reductase. Copper may also interact with oxygen species like superoxide anions and hydrogen peroxide and catalyze the reaction for production of reactive toxic hydroxyl radicals.

Due to inactivation of above enzymes haemolytic anemia occurs as the membrane of erythrocytes is damaged. Copper ions can also oxidizes hem iron and forms methaemoglobin which cannot bind with oxygen and by this blood loses its oxygen carrying capacity.

Liver can be damaged early due to high absorption of copper which causes hepatic mitochondrial dysfunction, cell necrosis and obstruction. In renal failure intravascular hemolysis plays an important role. The hem pigment released from hemolysis of erythrocytes, contain toxic copper which contributes to the damage of tubular epithelial cells of the kidney. Hypotension caused by severe vomiting, diarrhoea, gastrointestinal bleed may also contribute to renal failure. ${ }^{10}$

\section{Onset and duration of action}

1. Gastrointestinal symptoms like nausea, vomiting and crampy abdominal pain occurs immediately after the ingestion of copper sulphate.

2. Vomiting usually occurs within 15 minutes of ingestion.
3. In cases with severe poisoning cardiovascular symptoms can occur early within a few hours of poisoning.

4. Hematological symptoms occurs within 12-24 hours after ingestion of copper sulphate. ${ }^{2}$

\section{Fatal dose and fatal period}

1. The average oral lethal dose of Copper Sulphate in human is $30 \mathrm{gm}$ and Copper Subacetate is $15 \mathrm{gm}$. Both can cause death within 1 to 3 days ${ }^{12}$.

2. A minimal risk level (MRL) for copper toxicity due to acute-duration oral exposure (1-14 days) is $0.1 \mathrm{mg} / \mathrm{kg} /$ day.

3. A minimal risk level (MRL) for copper toxicity due to intermediate-duration oral exposure (15-365 days) is $0.1 \mathrm{mg} / \mathrm{kg} /$ day.

\section{Normal/reference value}

Normal and toxic levels of copper in the serum, blood, urine and tissue are given in the table1.

Table 1: Normal and toxic level of copper in biological samples

\begin{tabular}{|c|c|c|}
\hline Matrix & Normal Level & Toxic Level \\
\hline Serum (Free Copper) & $10-15 \mu \mathrm{g} / \mathrm{dL}$ & - \\
\hline Blood (Total Copper) & $0.6-1.5 \mu \mathrm{g} / \mathrm{ml}$ & $2 \mu \mathrm{g} / \mathrm{ml}$ \\
\hline 24 Hr Urine & $20-50 \mu \mathrm{g} / 24 \mathrm{Hr}$ & - \\
\hline Tissue & $20-50 \mu \mathrm{g} / \mathrm{g}$ & - \\
\hline
\end{tabular}

\section{Systemic effects on body}

1. Gastrointestinal System: Due to ingestion of copper sulphate it cause immediate effects on gastrointestinal tract, it cause erosions of mucous membrane, bleeding of gastrointestinal tract, burning epigastric sensation and hemetemesis. ${ }^{10,12,14,15}$

2. Cardiovascular System: In severe poisoning cases hypotension, tachycardia and cardiovascular collapse is seen within few hours of poisoning. Due to frequent blood lose due to several conditions like gastrointestinal blood lose, hematuria etc. hypovolemia occurs. Due to methemoglobinemia cardiac dysryhtmia and hypoxia is seen. ${ }^{10,12,14,15}$

3. Hematological System: Hemolysis occurs within 1224 hours of ingestion. Oxygen carrying capacity of blood decreases due to formation of methemoglobulin. Coagulopathy can occur due to direct effect of free copper ions on the coagulation cascade..$^{10,12,14,15}$

4. Hepatic System: Due to hemolysis jaundice appears after 2-3 days of poisoning. It also cause necrosis of hepatic cells and cause liver dysfunction..$^{10,12,14,15}$

5. Renal System: Renal failure can be caused due to damage of tubular epithelial cells due to hemolysis and excess of toxic copper in blood. Renal damage is usually observed within 3-4 days of poisoning. ${ }^{10,12,14,15}$

6. Central Nervous System: Severe poisoning can cause CNS depression ranging from lethargy to coma or seizure. ${ }^{10,12,14,15}$ 


\section{Clinical appearance}

Symptoms of acute poisoning by ingestion of copper salts are

1. Metallic taste of mouth.

2. Increase in production of saliva.

3. Severe pains that grips the abdomen.

4. Nausea and vomiting (vomitus is bluish or greenish in colour) which occur after few minutes of ingestion

5. Diarrhea

6. Muscular pain and tenderness

7. Pancreatitis

8. Methemoglobinemia

9. Hemolysis

10. Jaundice

11. Oliguria (low production of urine by kidney), anuria (no production of urine by kidney), albuminuria (presence of albumin protein in urine), hemoglobinuria (presence of haemoglobin in urine), hematuria (presence of blood in urine).

12. Convulsions (involuntary muscular contraction).

13. Delirium (a temporary state of mind with sudden onset).

14. Depression of Central Nervous System occurs which cause coma. ${ }^{10,12,14,15}$

Symptoms appearing due to inhalation and exposure of copper fumes or dust are

1. Irritation in respiratory tract

2. Cough

3. Conjunctivitis (inflammation of conjunctiva, which is clear mucous membrane and lines the inner surface of the eyelid and the exposed surface of the eyeball)

4. Metal fume fever. ${ }^{10,12,14,15}$

Symptoms of chronic poisoning are

1. Pain in abdomen

2. At the dental margins of gums a greenish line start to appear

3. Due to inhalation of copper sulphate from spraying pesticides in fields, farmers are infected by this Vineyard sprayer's lung disease

4. Due to accumulation of copper in hair colour of hair becomes green

5. Wilson's disease (an autosomal-recessive genetic disorder in which copper accumulates in tissues). ${ }^{10,12,14,15}$

\section{Diagnostic investigation}

Evaluation of copper level is helpful in the diagnosis of several diseases processes. This can be done by calculating total copper in the blood, free serum copper concentration, liver copper concentration etc.

1. If the history is not clear, serum and whole blood copper concentration is measured as soon as possible because an increase in serum copper concentration is seen within three hours of ingestion of copper sulphate, after that it gradually falls and attains its normal level within 17/hrs to 7 days. Then fall in blood copper level is attributed to increase in copper concentration in tissues like liver and kidney.

2. Haemoglobin level should be monitored as its concentration becomes less due to hemolysis because of excess copper inside the erythrocytes and it guides whether there is need of blood transfusion.

3. Monitoring of renal functions and electrolyte is essential to assess fluid status and extent of renal failure.

4. Examination of urine is also required for evidence of hemoglobinuria and hematuria and also to check 24/hours urine copper level. ${ }^{10}$

\section{Analytical toxicological analytical methods Qualitative analysis \\ Digestion of biological sample}

Biological sample is digested by wet classical method using mixture of different acids followed by dilution with ultra pure water. Now a days it is done by using microwave digestion system.

1. Group test: Two drops of aqueous solution of biological sample is taken in a spotted tile and few drops of ammonium hydroxide is added to it. A blue colour spot is obtained. Blue colour of spot is made acidic by adding few drops of acetic acid followed by few drops of potassium ferro-cyanide solution. A chocolate brown colour spot is obtained which confirms the presence of copper. ${ }^{16}$

2. Feigl's Test: Two drops of aqueous solution of the biological material is mixed with 2 drops of dilute zinc nitrate solution followed by two drops of mercuryammonium thiocyanate reagent in a test tube. A pink coloured precipitate is obtained, which confirms the presence of copper. ${ }^{16}$

3. Rubinic Acid Test: Aqueous solution of biological material is spotted on a piece of what man filter paper. The spot is dried and then sprayed with rubinic acid followed by exposure to ammonia vapours. An olive coloured spot appears which confirms the presence of copper. ${ }^{16}$

4. 2,2-Diquinolyl (Cuproin) Test: Two drops of aqueous solution of biological material $(\mathrm{pH} \geq 3)$ is placed on a spoted tile and several crystals of hydroxylamine hydrochloride is added to it. Three drops of a saturated ethanol solution of cuprion is added to above spoted tiles. Colour of spot changes from purple to pink, which confirms the presence of copper. ${ }^{16}$

5. Benzoinoxime Test: Aqueous solution of biological material is made less acidic by dilution with ultra pure water. Few drops of this solution is poured on a filter paper. One drop of 5\% alcoholic solution of benzoinoxime is add to it, and finally exposed with ammonia vapours. A green colour is observed, which confirms the presence of copper. ${ }^{16}$

\section{QuantitativeMethods}

1. UV-Visible Spectroscopy method: Copper can be detected quantitatively by using UV-Visible 
spectrophotometry. Copper can form complexed with organic compounds which will give absorbance at specified wavelength. ${ }^{12,18-21}$

2. Atomic Absorption Spectrophotometry method (AAS): Atomic absorption spectrophotometry (AAS) is good technique for the determination of Copper in biological materials. The absorbance of the standard solutions is plotted against the different concentration of Copper. The amount of Copper in biological material can be calculated from the calibration curve. ${ }^{17-21}$

3. Ion Chromatography: Ion chromatography is another important tool for the quantitative estimation of Copper in biological materials such as blood, urine, tissue, hair, nail etc.

4. Voltammetry/ Polarography method: Voltammetry/Polarography is another tool for quantitative analysis of Copper in biological materials in trace level. ${ }^{16}$

5. ICP-OES/ICP- MS Method: Inductively Coupled Plasma Optical Emission Spectroscopy/ (ICE-OES) is an analytical technique that uses the emission spectra to quantify the Copper. It is an advance technique for estimation of copper in biological sampling. Inductively Coupled Plasma Mass Spectrometry (ICP-MS) is the latest advance technique for determination of copper in microgram and nanogram and picogram levels.

6. Neutron Activation and Analysis (NAA): NAA is another technique for heavy metal analysis in biological sample.

\section{Management/Treatment of copper poisoning Household/ pre-hospital remedies \\ Decreasing absorption}

1. After acute ingestion of copper sulphate, one should immediate starts dilution with water or milk. Water may be used initially to dislodge adherent solid particles and to dilute the ingested copper sulphate.

2. Emesis should be avoided to prevent re-exposure of the esophagus to the corrosive agent. An antiemetic therapy may require because spontaneous vomiting is likely to occur in copper sulphate poisoning.

3. If patient presents within $30 \mathrm{~min}$ with large intentional ingestion of acid then narrow nasogastric tube suction can be used to remove the remaining acid in the gut.

4. Activated charcoal administration should be considered after a potentially dangerous ingestion. It is most effective when administered within one hour of ingestion. Use a minimum of $240 \mathrm{ml}$ of water per 30 gm charcoal.

\section{Supportive measures}

1. Management of corrosive burns

i. If suspecting corrosive damage to oesophageal or gastric region then upper GI endoscopy should be carried out, ideally within $12-24 \mathrm{~h}$, to observe the severity of injury. It will help in grading the injury caused by corrosive acids, planning the management of patients and also in predicting the prognosis.

ii. Sucralfate may help to relieve the symptoms of mucosal injury.

iii. Stricture formation are common in patients with grade III ulcers even on steroid administration. Moreover, steroids may mask or worsen the complications of corrosives in grade III patients and hence steroids are contraindicated.

2. Methemoglobinemia: If patients present with methemoglobinemia then it should be treated with methylene blue. It enhances the conversion of methemoglobin to hemoglobin by increasing the activity of the methemoglobin reductase enzyme. Dose is $1-2 \mathrm{mg} / \mathrm{kg} / \mathrm{dose}(0.1$ to $0.2 \mathrm{ml} / \mathrm{kg}$ of $1 \%$ solution) intravenously over 5 minutes. The dose may be repeated if cyanosis does not disappear within one hour.

3. Hypotensive episode: If patient present with hypotensive condition then it should be treated with fluids, dopamine and noradrenaline

\section{Chelation therapy}

In severely poisoned patients the presence of acute renal failure often limits the potential for antidotes.

1. Penicillamine: D-penicillamine has been used to treat acute copper intoxication, but data regarding efficacy are lacking.

2. Adult dose: 1000 to $1500 \mathrm{mg} /$ day divided every six to 12h, before meals. Pediatric dose: Initially $10 \mathrm{mg} / \mathrm{kg} / \mathrm{day}$, gradually increase to $30 \mathrm{mg} / \mathrm{kg} /$ day divided in two or three doses as tolerated.

Dimercaprol / BAL: Intramuscular BAL is probably appropriate in patients in whom vomiting and gastrointestinal injury prevents oral D-penicillamine administration. BAL- copper complex primarily undergoes biliary elimination and hence it is useful in patients with renal failure. Dose: 3 to $5 \mathrm{mg} / \mathrm{kg} /$ dose deep intramuscularly every four hours for two days, ever four to six hours for an additional two days, then every four to $12 \mathrm{~h}$ for up to seven additional days.

3. Edetate calcium disodium: The dose of this agent is 75 $\mathrm{mg} / \mathrm{kg} /$ day deep intramuscularly or slow intravenous infusion given in three to six divided doses for up to five days; may be repeated for a second course after a minimum of two days; each course should not exceed a total of $500 \mathrm{mg} / \mathrm{kg}$.

\section{Enhanced elimination}

Hemodialysis to remove copper is ineffective, but may be indicated in patients with renal failure secondary to copper poisoning. Peritoneal dialysis with salt-poor albumin resulted in extraction of more copper than dialysate without albumin 


\section{Conclusion}

Copper is an essential dietary metal which is required for various enzymatic processes in our body but concentration more than normal value can cause various disorders, disease and even it can cause death. Salts of copper are used for homicidal and suicidal poisoning, copper sulphate is mostly used for this purpose. After ingestion or exposure to salts of copper various clinical features appears which can be treated with chelation treatment, supportive measures etc. Detection of copper can be done by various analytival methods like UV-Visible Spectrophotomer, voltametric method and also by atomic absorption spectrophotometer.

\section{Source of Funding}

None.

\section{Conflict of Interest}

None.

\section{References}

1. https://en.wikipedia.org/wiki/Copper\#Toxicity, 10/06/2018.

2. Ashish Badiye, Neeti Kapoor \& Himanshu Khajuria. Copper Toxicity: A comprehensive study. Res J Recent science; vol2(ISC-2012); 2013:58-67.

3. M Angelova, S Asenova, V Nedkova, R Koleva-Kolarova. Copper in the human organism. Trakia J Sci 2011;9(1):88-98.

4. https://en.wikipedia.org/wiki/Copper(II)_sulfate, 11/06/2018.

5. Copper carbonate, basic- toxicity, ecological toxicity and regulatory information; PAN pesticides database-chemicals.

6. Cupric acetoarsenite- toxicity, ecological toxicity and regulatory information. PAN pesticides database-chemicals.

7. Copper arsenite; Hazardous substance fact sheet. New Jersey Department of Health and Senior Services.

8. Dr. Paul C Eck, Dr. Larry Wilson. Copper toxicity. Eck Institute of Applied Nutrition and Bioenergetics Ltd.

9. P. G. Georgopoulos, A Roy, M J Yonone-Lioy, R E Opiekun \& P J Lioy. Copper: Environmental dynamics and human exposure issues. 2001; Journal of toxicology and environment health part B.

10. Kavita Saravul, Jimmy Jose, Mahadeva N Bhat, Beena Jimmy, BA Shastryl. Acute ingestion of copper sulphate: A review on its clinical manifestation and management. Indian J Crit Care Med 2007;11:274-80.

11. Judith R Turnlund; Human whole-body copper metabolism; Am J Clin Nutr 1998;1-67; page no-960S-964S.

12. Rajesh Bardale; Principles of Forensic Medicine And Toxicology;1st edition; 2011; Jaypee Brothers Medical Publishers (P) Ltd, New Delhi.

13. https://emedicine.medscape.com/article/2087780-overview, $21 / 07 / 2018$

14. Champika SSK Gamakarange, Rodrigo C, Weerasinghe S, Gnanathasan A, Puvanaraj V and Fernando H et al. Complications and management of acute copper sulphate poisoning; a case discussion; J Occup Med Toxicol 2011;1-6; page no-34.

15. Ricardo Uauy, Manuel Olivares and Mauricio Gonzalez; Essentiality of copper in human; Am J Clin Nutr 1998;952S959S.

16. K. Jaiswal and T. Millo; Hand Book of Forensic Analytical Toxicology, 1st edition; 2014; Jaypee Brothers Medical Publishers (P) Ltd, New Delhi.

17. Atamjyot, Jain P and B. K. Puri; Atomic absorption spectrometric determination of copper after adsorption of its sodiumdi ethyldithiocarbamate complex on a new polymeric adsorbent; Indian J Chem 2006;1-45A; page no- 409-411.

18. C. A. Elvehjem and C. W. Lindow; The determination of copper in biological materials; J Cell Biol

19. Cartwright E. George, Jones J. Patricia and Wintrobe M. Maxwell; A method for the determination of copper in blood serum; J Cell Biol

20. Determination of multiple analytes; CHEM 334 quantitative analysis laborartory; Colorado state university; 2018; page no$1-2$.

21. Gwendolyn A. McMillin, PhD, James J. Travis, John W. Hunt; Direct measurement of free copper in serum or plasma ultrafiltrate; $2009 ; 131 ;(2) ; 160-5$.

22. Ahmed MJ, Jahan I and banoo S; A simple spectrophotometric method for the determination of copper in industrial, environment, biological amd soil samples using 2,5Dimercapto-1,3,4-thiadiazole; the Japan society for analytical chemistry; 2002;18;805-10.

How to cite this article: Jaiswal AK, Bhatia D, Rajesh, Gupta M, Millo T. Analytical aspects and management of copper poisoning- A review. Indian J Forensic Community Med 2019;6(3):110-5. 